- Most cases of dry mouth are caused by inadequate fluid intake, or by excess fluid loss - for example in diabetes.

- Drugs are a common cause of hyposalivation.

- Hyposalivation also follows irradiation but some systemic diseases may present in this way.

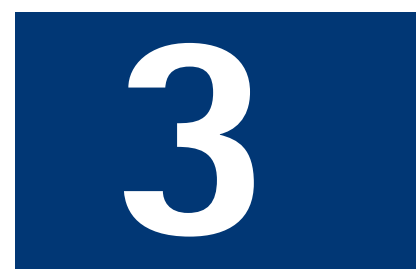

\title{
Oral Medicine - Update for the dental practitioner. Dry mouth and disorders of salivation
}

\author{
C. Scully ${ }^{1}$ and D. H. Felix ${ }^{2}$
}

This series provides an overview of current thinking in the more relevant areas of oral medicine for primary care practitioners, written by the authors while they were holding the Presidencies of the European Association for Oral Medicine and the British Society for Oral Medicine, respectively. A book containing additional material will be published. The series gives the detail necessary to assist the primary dental clinical team caring for patients with oral complaints that may be seen in general dental practice. Space precludes inclusion of illustrations of uncommon or rare disorders, or discussion of disorders affecting the hard tissues. Approaching the subject mainly by the symptomatic approach - as it largely relates to the presenting complaint - was considered to be a more helpful approach for GDPs rather than taking a diagnostic category approach. The clinical aspects of the relevant disorders are discussed, including a brief overview of the aetiology, detail on the clinical features and how the diagnosis is made. Guidance on management and when to refer is also provided, along with relevant websites which offer further detail.

\section{ORAL MEDICINE \\ 1. Aphthous and other common ulcers \\ 2. Mouth ulcers of more serious connotation \\ 3. Dry mouth and disorders of salivation \\ 4. Oral malodour \\ 5. Oral white patches \\ 6. Oral red and hyperpigmented patches \\ 7. Orofacial sensation and movement \\ 8. Orofacial swellings and lumps \\ 9. Oral cancer \\ 10. Orofacial pain \\ 1*Professor, Consultant, Dean, Eastman Dental Institute for Oral Health Care Sciences, 256 Gray's Inn Road, UCL, \\ University of London, London WC1X 8LD \\ ${ }^{2}$ Consultant, Senior Lecturer, Glasgow Dental Hospital and School, 378 \\ Sauchiehall Street, Glasgow G2 3JZ | \\ Associate Dean for Postgraduate Dental \\ Education, NHS Education for Scotland, \\ 2nd Floor, Hanover Buildings, 66 Rose \\ Street, Edinburgh EH2 2NN \\ ${ }^{*}$ Correspondence to: Professor Crispian Scully CBE \\ Email:c.scully@eastman.ucl.ac.uk}

\section{Refereed Paper}

( ) British Dental Journal 2005; 199

423-427
Saliva is essential to oral health. The most obvious and important function of saliva is in eating, for taste and to lubricate food and protect the mucosa and teeth. The water, mucins and proline-rich glycoproteins lubricate food and help swallowing, and saliva is essential for normal taste perception. Saliva is protective via the washing action, via various antimicrobial components such as mucin, histatins, lysozyme and lactoferrin, and via specific antibodies to a range of micro-organisms that the host has encountered.

Salivary gland secretion from the major (parotid, submandibular and sublingual) and minor glands (multiple mucous glands scattered throughout the mouth - especially the lips and soft palate) is mainly under neural control, under the influence of the autonomic nervous system, although various hormones may also modulate its composition. In general, parasympathetic stimulation increases salivation, while sympathetic stimulation produces more viscous saliva and therefore appears to depress salivation.

Thus, in acute anxiety, when there is sympathetic stimulation, the mouth feels dry. The mouth is also dry if the parasympathetic system is inhibited by, for example, various drugs. Anything that damages the glands, or reduces body fluids can also reduce salivation.

\section{DRY MOUTH (XEROSTOMIA)}

Dry mouth (xerostomia) is a complaint that is the most common salivary problem and is the subjective sense of dryness which may be due to:
- Reduced salivary flow (hyposalivation) and/or

- Changed salivary composition.

Patients who have chronically decreased salivary flow (hyposalivation) suffer from lack of oral lubrication, affecting many functions, and they may complain of dryness (xerostomia), and can develop dental caries and other infections (candidosis, or acute bacterial sialadenitis) as a consequence of the reduced defences.

\section{Causes}

There are physiological causes of hyposalivation. Thus a dry mouth is common during periods of anxiety, due to sympathetic activity; mouthbreathers may also have a dry mouth and advancing age is associated with dry

\begin{tabular}{l} 
Table 1 Causes of dry mouth \\
\hline latrogenic \\
Drugs \\
Irradiation \\
Graft versus host disease \\
Disease \\
Dehydration \\
Psychogenic \\
Salivary gland disease \\
Sjögren's syndrome \\
Sarcoidosis \\
Salivary aplasia
\end{tabular}


mouth probably because of a reduction of salivary acini, with a fall in salivary secretory reserve.

Very rarely, children are born missing salivary glands - so-called salivary gland aplasia or agenesis. Most salivary gland dysfunction however is acquired (Table 1).

Drugs, in most older people complaining of xerostomia, are the cause. Indeed, the main causes of dry mouth are iatrogenic. There is usually a fairly close temporal relationship between starting the drug treatment or increasing the dose, and experiencing the dry mouth. However, the reason for which the drug is being taken may also be important. For example, patients with anxiety or depressive conditions may complain of dry mouth even in the absence of drug therapy (or evidence of reduced salivary flow).

Drugs recognised as causes of reduced salivation include mainly those with anticholinergic, or sympathomimetic, or diuretic activity. These include those shown in Table 2. Irradiation for malignant tumours in the head

\begin{tabular}{l} 
Table 2 Drugs associated with dry mouth \\
\hline Drugs which directly damage the salivary glands \\
Cytotoxic drugs \\
Drugs with anticholinergic activity \\
Anticholinergic agents such as atropine, atropinics and \\
hyoscine \\
Antireflux agents eg proton-pump inhibitors (such as \\
omeprazole) \\
Psychoactive agents with anticholinergic activities such as: \\
Antidepressants, including tricyclic (eg amitriptyline, \\
nortriptyline, clomipramine and dothiepin [dosulepin]), \\
selective serotonin re-uptake inhibitors (eg fluoxetine), \\
lithium and others. \\
Phenothiazines \\
Benzodiazepines \\
Opioids \\
Antihistamines \\
Bupropion \\
Drugs acting on sympathetic system \\
Drugs with sympathomimetic activity eg ephedrine \\
Antihypertensives; alpha 1 antagonists (e.g. terazosin and \\
prazosin) and alpha 2 agonists (e.g. clonidine) may reduce \\
salivary flow. Beta blockers (e.g. atenolol, propranolol) also \\
change salivary protein levels. \\
Drugs which deplete fluid \\
Diuretics \\
Drom
\end{tabular}

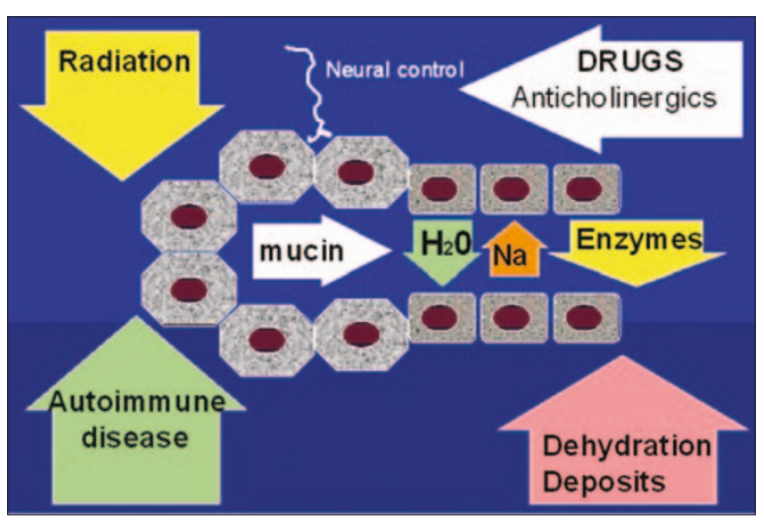

and neck region, such as oral cancer, can produce profound xerostomia. Other sources of irradiation such as radioactive iodine $\left({ }^{131} \mathrm{I}\right)$ used for treating thyroid disease, may also damage the salivary glands, which take up the radioactive iodine.

Dehydration, as in diabetes mellitus, chronic renal failure, hyperparathyroidism, any fever or diabetes insipidus can cause xerostomia.

Diseases of salivary glands can also cause salivary dysfunction. These are mainly Sjögren's syndrome (a multisystem auto-immune condition discussed below); sarcoidosis; HIV disease; hepatitis $C$ virus infection; liver diseases; and cystic fibrosis (mucoviscidosis) (Fig. 1).

Finally, it is important to also recognise that some patients complaining of a dry mouth have no evidence of a reduced salivary flow or a salivary disorder (ie they have xerostomia but not hyposalivation), and in these there may be a psychogenic reason for the complaint.

\section{Clinical features}

The patient with hyposalivation may have difficulty in:

- Swallowing - especially dry foods such as biscuits (the cracker sign)

- Controlling dentures

- Speaking, as the tongue tends to stick to the palate - leading to 'clicking' speech.

Patients may also complain of unpleasant taste or loss of sense of taste, or halitosis.

The patient with hyposalivation may complain of a dry mouth or these sequelae alone, or also complain of dryness of the eyes and other mucosae (nasal, laryngeal, genital). Those with eye complaints have blurring, light intolerance, burning, itching or grittiness, and sometimes an inability to cry.

Systemic features (such as joint pains) may be suggestive of Sjögren's syndrome.

Examination may reveal that the lips adhere one to another and an examining dental mirror may stick to the mucosa because of the reduced lubrication. Lipstick or food debris may be seen sticking to the teeth or soft tissues, and the usual pooling of saliva in the floor of the mouth may be absent. Thin lines of frothy saliva may form along lines of contact of the oral soft tissues, on the tongue, or in the vestibule. Saliva may not be expressible from the parotid ducts. The tongue is dry (Fig. 2) and may become characteristically lobulated and usually red, with partial or complete depapillation (Fig. 3).

Complications of hyposalivation can include:

- Dental caries - which tends to involve smooth surfaces and areas otherwise not very prone to caries - such as the lower incisor region and roots. Hyposalivation may explain patients with uncontrollable recurrent caries, who are apparently complying with dietary advice. 


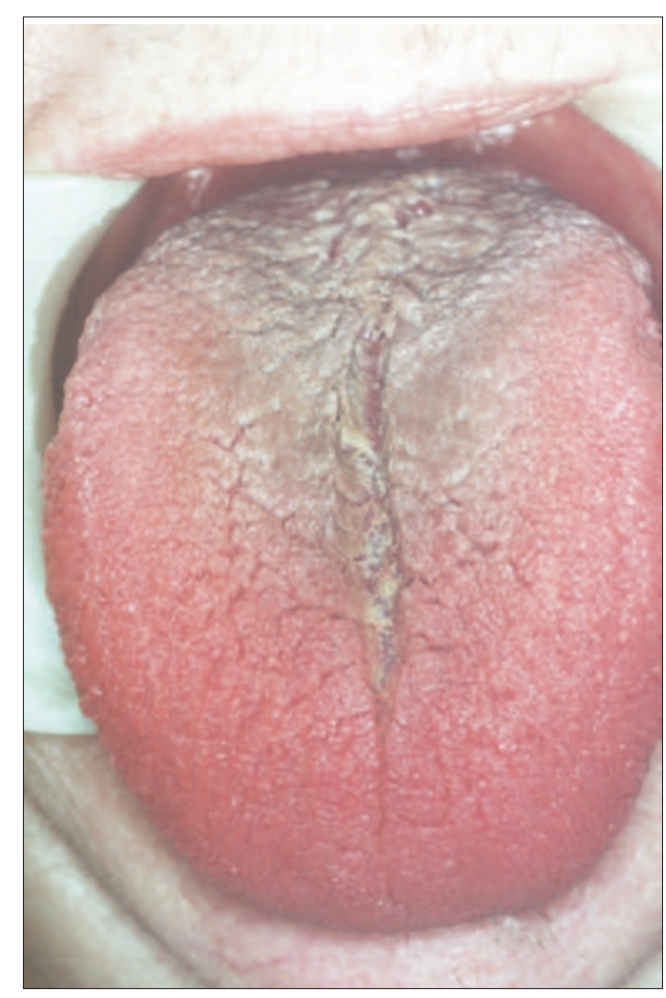

Fig. 2 Dry mouth

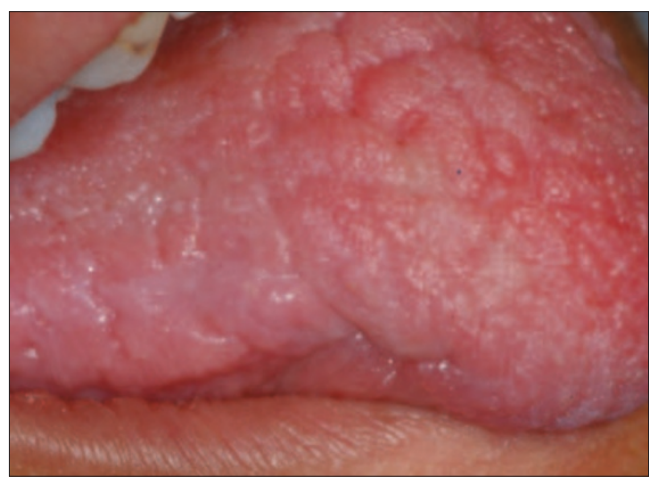

Fig. 3 Dry mouth and lobulated tongue

- Candidosis (Fig. 4) - which may cause a burning sensation or mucosal erythema, lingual filiform papillae atrophy, and angular stomatitis (angular cheilitis)

- Halitosis (Article 4)

- Ascending (suppurative) sialadenitis - which presents with pain and swelling of a major salivary gland, and sometimes purulent discharge from the duct.

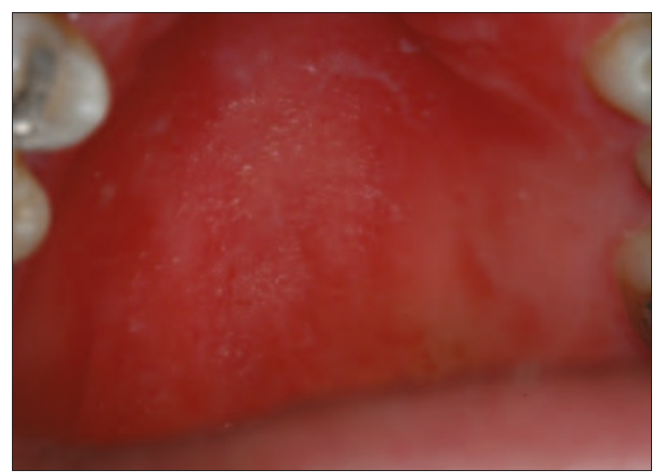

Fig. 4 Dry mouth complicated by candidosis

\section{Diagnosis}

Hyposalivation is a clinical diagnosis which can be made by the practitioner predominantly on the basis of the history and examination.

It can be helpful to document salivary function by salivary function studies such as salivary flow rates (sialometry). Collection of whole saliva (oral fluid) is currently the routine technique for sialometry used by many clinicians, despite the fact that it is rather inaccurate and non-specific. It is usually carried out by allowing the patient to sit quietly and dribble into a measuring container over 15 minutes; in a normal person, such an unstimulated whole saliva flow rate exceeds $1.5 \mathrm{ml} / 15 \mathrm{~min}(0.1 \mathrm{ml} / \mathrm{min})$.

The specialist may be needed to:

- Study and document the degree of salivary dysfunction

- Determine the cause

- Arrange future dental care although much of this can be undertaken in the primary care environment.

Investigations may be indicated to exclude systemic disease, particularly to exclude:

- Sjögren's syndrome and connective tissue disorders

- Diabetes

- Sarcoidosis

- Viral infections (hepatitis C; HIV).

Commonly used investigations may thus include:

- Blood tests (mainly to exclude diabetes,

Sjögren's syndrome, sarcoidosis, hepatitis and other infections)

- Eye tests (eg Schirmer test mainly to exclude Sjögren's syndrome)

- Salivary gland biopsy (if there is suspicion of organic disease such as Sjögren's syndrome )

- Imaging (mainly to exclude Sjögren's syndrome, sarcoidosis or neoplasia).

It is important to remember, as stated above, that in some patients complaining of a dry mouth no evidence of a reduced salivary flow or a salivary disorder can be found. There may then be a psychogenic reason for the complaint.

\section{Management (see below)}

\section{SJÖGREN'S SYNDROME}

Sjögren's syndrome (SS) is an uncommon condition, the association of dry mouth and dry eyes. The other key features of SS are evidence of an autoimmune reaction shown usually by serum autoantibodies and sometimes confirmed by demonstrating mononuclear cell infiltrates in a labial salivary gland biopsy. Sjögren's syndrome can affect any age but the onset is most common in middle age or older. The majority of patients are women.

\section{Aetiopathogenesis}

SS is an autoimmune disease affecting mainly exocrine glands like the salivary glands, lacrimal

\section{Keypoints for dentists:} dry mouth

Diagnosis is clinical but investigations may be indicated, including:

- Blood tests (ESR and SS-A and SSB antibodies; see below)

- Eye tests (Schirmer; see below)

- Urinalysis

- Salivary flow rate tests (sialometry)

- Salivary gland biopsy (labial gland biopsy)

- Imaging

- Chest radiograph

- Sialography

- Scintiscanning

- Ultrasound

Key points for patients:

\section{dry mouth}

- Saliva helps swallowing, talking, and taste, and protects the mouth

- Where saliva is reduced there is a risk of dental decay (caries), halitosis, altered taste, mouth soreness and infections

- Saliva may be reduced by radiotherapy or chemotherapy, various drugs, after bone marrow transplant, in diabetes, in some viral infections, in anxiety/stress/depression, or in salivary gland disorders.

- Diagnosis is clinical but investigations may be indicated, including

- Blood tests

- Eye tests

- Urinalysis

- Salivary flow rate

- Salivary gland biopsy

- X-rays or scans 
glands and pancreas. There may be a viral aetiology and a genetic predisposition.

The most common type of SS is secondary Sjögren's syndrome (SS-2) which comprises dry eyes and dry mouth and a connective tissue or autoimmune disease usually rheumatoid arthritis (RA) (Table 3). However, SS can appear by itself, and in the absence of a connective tissue disease is often termed sicca syndrome, usually referred to as primary Sjögren's syndrome (SS1). Nevertheless, both forms are chronic and can affect not only the salivary glands (Fig. 5), but also extraglandular tissues. Chronic B lymphocyte stimulation can occasionally lead to B cell neoplasms such as lymphoma.

\begin{tabular}{|c|c|c|}
\hline & SS-1 & SS-2 \\
\hline Dry mouth & Yes & Yes \\
\hline Dry eyes & Yes & Yes \\
\hline $\begin{array}{l}\text { Connective tissue } \\
\text { disease }\end{array}$ & No & Yes \\
\hline $\begin{array}{l}\text { Extraglandular } \\
\text { problems }\end{array}$ & More common & Less common \\
\hline
\end{tabular}

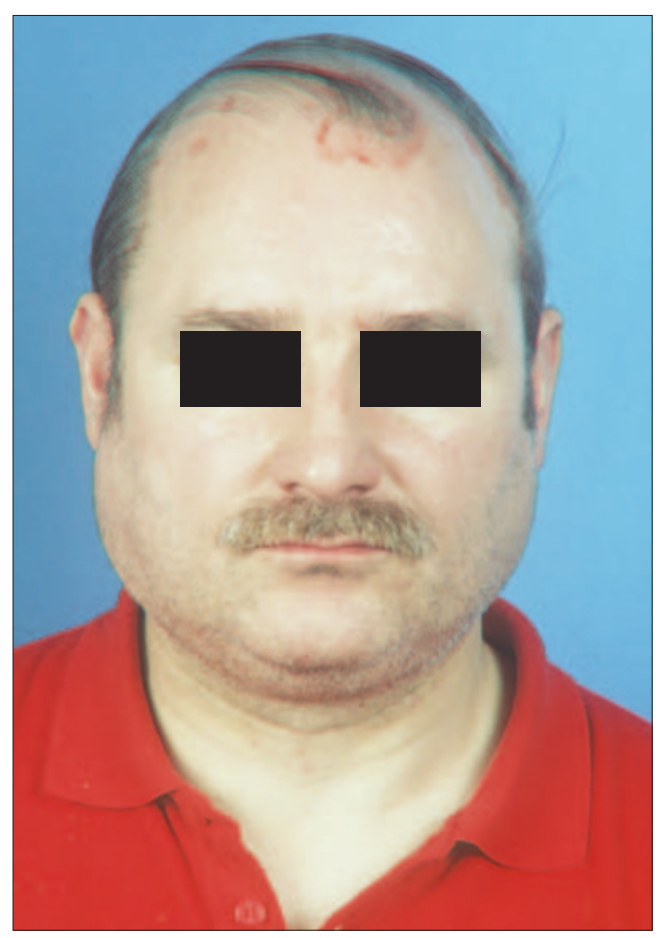

SS is often characterised by a raised erythrocyte sedimentation rate (ESR) and several autoantibodies - particularly antinuclear factor (ANF) and rheumatoid factor (RF), and more specific antinuclear antibodies known as SS-A (Ro) and SS-B (La).

\section{Clinical features}

SS presents mainly with eye complaints which include sensations of grittiness, soreness, itching, dryness, blurred vision or light intolerance. The eyes may be red with inflammation of the conjunctivae and soft crusts at the angles (keratoconjunctivitis sicca). The lacrimal glands may swell.
Oral complaints (often the presenting feature) including:

- Xerostomia

- Swollen salivary glands; causes include chronic sialadenitis as part of the fundamental autoimmune disease process, ascending bacterial sialadenitis which can arise if bacteria ascend the ducts because salivation is impaired, benign lymphoepithelial lesions/ myoepithelial sialadenitis (pseudolymphoma) and lymphoma (Fig. 6).

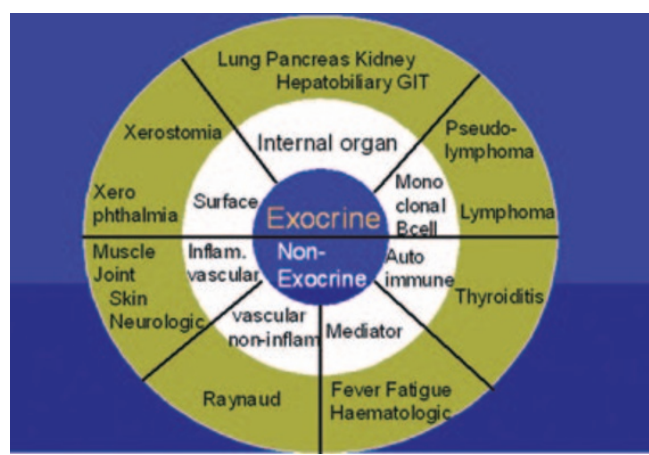

Fig. 6 Complications of Sjögren's syndrome

However, SS is a more generalised disorder which involves not only the exocrine salivary and lacrimal glands, but can have a range of other complications, summarised in Figure 6.

\section{Diagnosis}

Diagnosis is made from the history and clinical features, and may be confirmed by autoantibody studies and sometimes by other investigations such as sialometry and labial salivary gland biopsy. In specialist units various international criteria are used to confirm the diagnosis. There is no specific treatment yet for SS, but the hyposalivation can be managed, and dental preventive care is essential. The dental team have an important role to play in this.

\section{Management of hyposalivation}

Any underlying cause of xerostomia should if possible be rectified; for example, xerostomiaproducing drugs may be changed for an alternative, and causes such as diabetes should be treated.

Patients should be educated into efforts to avoid factors that may increase dryness, and to keep the mouth moist (Table 4).

Salivary substitutes may help symptomatically. A variety are available including:

- Water or ice chips; frequent sips of water are generally effective

- Synthetic salivary substitutes (Table 5).

As patients with objective xerostomia are at increased risk of developing caries it is important that they take a non-cariogenic diet and maintain a high standard of oral hygiene. The regular use of topical fluoride agents forms an important component of their long-term care.

Salivation may be stimulated by using diabetic sweets or chewing gums (containing 


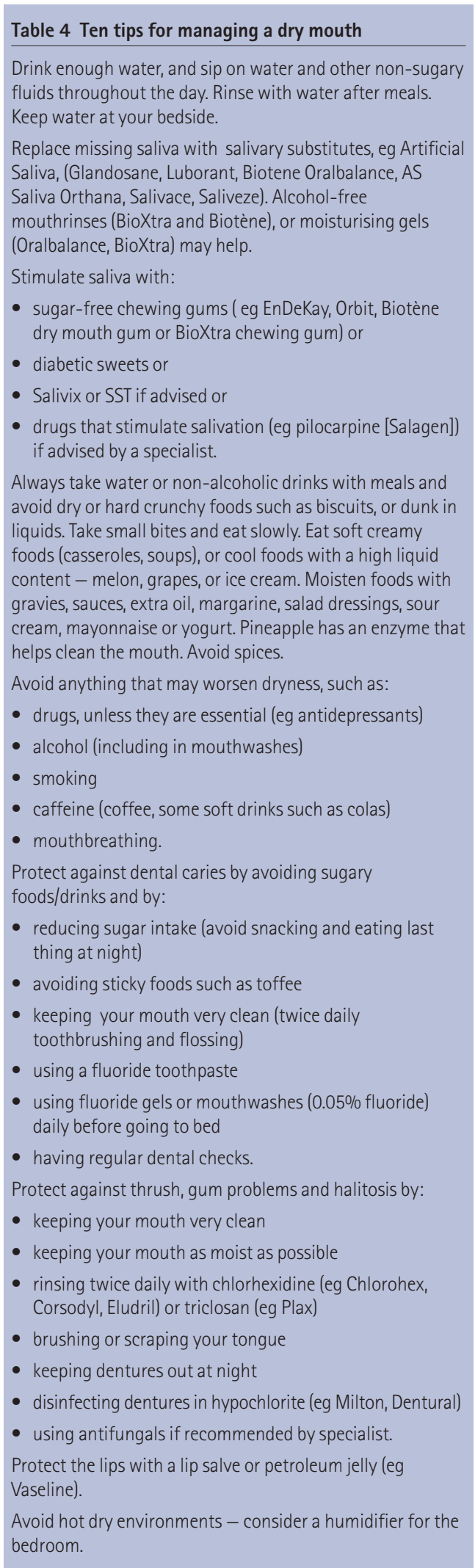

sorbitol or xylitol, not sucrose). Cholinergic drugs that stimulate salivation (sialogogues), such as pilocarpine, or cevimeline should be used only by a specialist. Oral complications should be prevented and treated.

Useful websites:

- http://www.arc.org.uk/about_arth/booklets/6041/6041.htm

\begin{tabular}{|c|c|c|c|c|}
\hline UK trade names & Offered as & $\begin{array}{l}\text { Contains } \\
\text { fluoride }\end{array}$ & $\begin{array}{l}\text { Main } \\
\text { constituents }\end{array}$ & Comments \\
\hline AS Saliva Orthana & $\begin{array}{l}\text { Spray } \\
\text { or lozenge }\end{array}$ & $+1-$ & $\begin{array}{l}\text { Mucin } \\
\text { Xylitol }\end{array}$ & $\begin{array}{l}\text { Spray contains fluoride } \\
\text { but is unsuitable if there } \\
\text { are religious objections } \\
\text { to porcine mucin }\end{array}$ \\
\hline Biotene Oralbalance & Gel & - & $\begin{array}{l}\text { Glycerate polymer } \\
\text { base, lactoperoxidase, } \\
\text { glucose oxidase, xylitol }\end{array}$ & \\
\hline BioXtra & Gel & - & $\begin{array}{l}\text { Colostrum, } \\
\text { lactoperoxidase, } \\
\text { glucose oxidase, xylitol }\end{array}$ & \\
\hline Luborant & Spray & + & Carboxymethylcellulose & May contain fluoride \\
\hline Glandosane & Spray & - & Carboxymethylcellulose & \\
\hline \multicolumn{5}{|l|}{ Salivace } \\
\hline Saliveze & & & & \\
\hline
\end{tabular}

- http://www.nidcr.nih.gov/HealthInformation/DiseasesAndConditions/SjogrenSjögrensSyndrome.htm

- http://www.sjsworld.org/

- http://www.nidcr.nih.gov/HealthInformation/DiseasesAndConditions/DryMouthXerostomia/drymouth.htm

- http://www.oralcancerfoundation.org/dental/xerostomia.htm

\section{SIALORRHOEA (HYPERSALIVATION; PTYALISM)}

Infants frequently drool but this is normal. The complaint of sialorrhoea (excess salivation) is uncommon and may be true salivary hypersecretion - usually caused by physiological factors such as menstruation or early pregnancy, local factors such as teething or oral inflammatory lesions, food or medications (those with cholinergic activity such as pilocarpine, tetrabenazine, clozapine), or by nasogastric intubation. In some cases, apparent hypersalivation is caused not by excess saliva production but by an inability to swallow a normal amount of saliva (false sialorrhoea) caused by neuromuscular dysfunction (eg in Parkinson's disease, cerebral palsy, or learning disability) or by pharyngeal or oesophageal obstruction, such as by a neoplasm.

Treatment is of the underlying cause if possible and then the use of behavioural approaches or antisialogogues. Occasionally, surgery to redirect the salivary gland ducts into the oropharynx may be helpful. 